\title{
Proceeding
}

Supplementary Issue: Rio 2016 Olympic Games Third Anniversary Special Edition. Olympic Studies Forum, 2-3 September 2019. Federal University of Sergipe, Aracaju, Brazil

\section{Olympic Philosophy: An experience report of the approach to the transteoric model to measure motivation in the practice of physical activity Filosofia olímpica: Relato de experiência de abordagem do modelo transteórico para mensurar a motivação à prática de atividade física}

\author{
RICARDO VELA DE BRITTO-PEREIRA ${ }^{1}$, SARA FANTIN RIBEIRO ENGEL ${ }^{2}$, FABIANA CRISTINA \\ TURELLI-THUMÉ3 \\ ${ }^{1}$ Brazilian Air Force, Brazil \\ ${ }^{2}$ Federal University of Santa Catarina, Brazil \\ ${ }^{3}$ Autonomous University of Madrid, Spain
}

\begin{abstract}
The Olympic values proposed by Pierre de Coubertin are not always found in sports activities. This paper aims to identify the stages of behavioral change for physical activity in philosophy students following a syllabus based on the philosophy of Olympism. This study deals with a descriptive field research with quantitative and cross-sectional approach in which the convenience sample consisted of 180 female and male athletes participating in amateur Olympic Games for 2015; 161 for 2017 and 282 athletes for 2019, with participants from nine Brazilian states - Rio Grande do Sul, Santa Catarina, Paraná, Sao Paulo, Mato Grosso do Sul, Rio de Janeiro, Espírito Santo, Minas Gerais and Bahia. The stages of behavior change were analyzed using the Transtheoretical Model presented by Prochaska, DiClemente and collaborators, in the 1980s, in their pre-contemplation, contemplation, preparation, action and maintenance stages with qualitative research through monthly meetings with the instructors responsible for the project in each state; and through quantitative research at the Olympic Games. The results showed that athletes have been more motivated after the implementation of the Olympic values promotion program. Keywords: Olympic Philosophy; Behavior change; Transtheoretical Model; Sport; Formation in Values.
\end{abstract}

Cite this article as:

de Britto-Pereira, R.V., Engel, S.F.R., \& Turelli-Thumé, F.C. (2020). Olympic Philosophy: An experience report of the approach to the transteoric model to measure motivation in the practice of physical activity (in Portuguese). Journal of Human Sport and Exercise, 15(1proc), S71-S83. doi:https://doi.org/10.14198/jhse.2020.15.Proc1.08

\footnotetext{
Corresponding author. Brazilian Air Force, Brazil. https://orcid.org/0000-0003-1473-2889

E-mail: ricardoestatistico@yahoo.com.br

Supplementary Issue: Rio 2016 Olympic Games Third Anniversary Special Edition. Olympic Studies Forum, 2-3 September 2019. Federal University of Sergipe, Aracaju, Brazil.

JOURNAL OF HUMAN SPORT \& EXERCISE ISSN 1988-5202

(c) Faculty of Education. University of Alicante

doi:10.14198/jhse.2020.15.Proc1.08
} 


\section{RESUMO}

Os valores olímpicos propostos por Pierre de Coubertin, nem sempre se encontram nas atividades esportivas. Este artigo tem como objetivo identificar os estágios de mudança de comportamento para atividade física em estudantes de filosofia à maneira clássica, após um programa de estudos baseado na filosofia do olimpismo. 0 presente estudo trata de uma pesquisa de campo, descritiva, com abordagem quantitativa e corte transversal no qual a amostra do tipo conveniência foi constituída por 180 atletas dos sexos feminino e masculino participantes de Jogos Olímpicos amadores para o ano de 2015; 161 para 0 ano de 2017 e 282 atletas para o ano de 2019, existindo participantes de nove estados do Brasil - Rio Grande do Sul, Santa Catarina, Paraná, São Paulo, Mato Grosso do Sul, Rio de Janeiro, Espírito Santo, Minas Gerais e Bahia. Os estágios de mudança de comportamento foram analisados utilizando o Modelo Transteórico apresentado por Prochaska, DiClemente e colaboradores, na década de 1980, em suas etapas de pré-contemplação, contemplação, preparação, ação e manutenção com pesquisa qualitativa através de reuniões mensais com os instrutores responsáveis pelo projeto em cada Estado; e por meio de investigação quantitativa nos Jogos Olímpicos. Os resultados apontaram que os atletas têm apresentado maior motivação após a implementação do programa de promoção dos valores olímpicos. Palavras-chave: Filosofia Olímpica; Mudança de comportamento; Modelo Transteórico; Esporte; Formação em Valores. 


\section{INTRODUÇÃO}

O objeto de estudo deste trabalho é a Filosofia do Olimpismo e sua aplicabilidade à vida prática. Pierre de Coubertin é tradicionalmente conhecido como o principal responsável pelo resgate dos valores morais que encontram no esporte um meio adequado para serem praticados. Esses valores parecem ser os mesmos presentes já entre os gregos do período clássico e sua Filosofia (Parry, 2006).

Inúmeros são os relatos que se podem encontrar na literatura, teóricos e práticos, acerca da vivência dos valores olímpicos nas diferentes modalidades esportivas (Parry, 1998a; 1998b; Gomes, 1999; Amat \& Batalla, 2000; Carvalhedo \& Da Costa, 2000; Gomes \& Turini, 2004; Bento, 2007; entre outros). Entretanto, também se pode verificar a realização de atividades esportivas bastante afastadas das finalidades propostas pelo Barão de Coubertin. Com este estudo se pretende relatar a necessidade percebida de aliar rotinas de treinamento com o sentido ou significado que a Filosofia do Olimpismo oferece. Ou seja, utilizar o esporte como um meio eficaz para exercitar a filosofia, uma vez que a proposta do Olimpismo é a de uma Filosofia de Vida (Carta Olímpica, 2015).

Deste modo, este artigo apresenta-se como um dos resultados de um processo observado junto a atletasestudantes de Filosofia à Maneira Clássica em nove Estados do Brasil ${ }^{1}$ durante o período de 2015 a 2019. O objetivo traçado foi identificar os estágios de mudança de comportamento (Prochaska et al, 1992) para realização de atividade física nos estudantes integrantes do projeto após um Programa de estudos baseado na Filosofia do Olimpismo.

O referido projeto foi levado a cabo pela Escola do Esporte situada no Brasil, uma vez que esta é uma Organização Internacional desenvolvendo-se em 16 países distribuídos entre América e Europa. Trata-se de uma escola que se empenha em promover o esporte associado sempre à Filosofia, o que justifica 0 trabalho em parceria com a Organização Internacional Nova Acrópole. Assim, um requisito para os praticantes destes nove estados é que sejam estudantes de Filosofia, o que gera aporte para compreender a profundidade da Filosofia do Olimpismo e, por sua vez, que assumam como válido o Programa de Formação de Valores que é implementado pela Escola do Esporte.

O Programa de Formação de Valores da Escola do Esporte é igualmente uma proposta internacional. No Brasil, tal Programa foi implementado a partir de um coordenador nacional do projeto que ministrou a formação para coordenadores estaduais, em cada um dos nove Estados envolvidos. Os coordenadores estaduais por sua vez foram os incumbidos de transmitir essa formação para todos os atletas-estudantes de seus respectivos Estados. Todos os envolvidos, sejam coordenadores ou atletas, eram/são voluntários e assumiram os custos advindos de suas práticas².

Ainda que nas páginas seguintes serão apresentados os resultados, se pode aqui apontar que a compreensão da Filosofia do Olimpismo promove uma qualificação dos atletas-estudantes, permitindo a continuidade do trabalho. Sendo assim, entende-se como relevante compartilhar a experiência, bem seja por meio deste artigo, bem seja por comunicações orais em Congressos e Fóruns de Filosofia Olímpica e trabalhos realizados em parceria com o Comitê Brasileiro Pierre de Coubertin. Além disso, possivelmente se pode indicar com este trabalho prático possibilidades de aplicação da Filosofia, tornando o esporte uma

\footnotetext{
${ }_{1}^{1}$ Rio Grande do Sul, Santa Catarina, Paraná, São Paulo, Mato Grosso do Sul, Rio de Janeiro, Espírito Santo, Minas Gerais e Bahia.

2 Como viagem, por exemplo, para participar de Jogos organizados em nível nacional, ou mesmo uniformes de treinamento.
} 
ferramenta efetiva para mudança de comportamento. Ou seja, na mesma proporção que a mudança de comportamento pode levar à realização de atividade física, a opção por fazer atividade física, ou esporte mais propriamente, conduz à mudança de comportamento.

\section{MATERIAIS E MÉTODOS}

Esse estudo é caracterizado como descritivo/exploratório e traz como relato a experiência pedagógica desenvolvida pela Escola do Esporte, nas 27 filiais ou sub-escolas distribuídas em nove estados brasileiros anteriormente citados, no período de 2015 até setembro de 2019. Utiliza-se da etnografia para a coleta dos dados, com seus instrumentos diário de campo e registros fotográficos para relatar a experiência nesse artigo.

A etnografia é uma metodologia de pesquisa que vem sendo muito utilizada nos estudos realizados no campo da Educação. Esse tipo de pesquisa qualitativa foi adotado uma vez que possibilita uma relação bastante interativa entre o sujeito e o objeto da investigação (Molina Neto \& Bossle, 2010). Ancorado na colaboração do referido autor, que aponta essa metodologia como importante instrumento para que os educadores possam produzir conhecimento a partir das vivências práticas e refletir sobre sua intervenção, optou-se por sistematizar as experiências dos autores enquanto coordenadores, instrutores e atletas do projeto por meio do presente artigo.

O enfoque escolhido para ser aprofundado no relato foi entender como ocorre o processo de motivação dos alunos para iniciar a participação nas atividades físicas promovidas pela Escola do Esporte o que, por sua vez, implica em falar de mudança comportamental. Segundo a literatura, mudança de comportamento para a prática de atividade física é respaldada por diferentes teorias e modelos teóricos, dentre eles os modelos transteóricos têm sido cada vez mais utilizados (Toral \& Slater, 2007).

O Modelo Transteorético de Mudança (MTT) foi desenvolvido por Prochaska, DiClemente e Norcross (1992), para descrever os diferentes estágios envolvidos na aquisição ou manutenção de um comportamento, sendo conhecido também como Teoria dos Estágios de Mudança de Comportamento (Meurer, 2008). Nesse processo de mudança, o modelo prevê que as pessoas passam por cinco estágios distintos, à medida que avaliam a relevância do comportamento para suas vidas, passam a tomar atitudes, fortalecendo sua intenção de se modificar, podendo chegar a conquista da meta de adotar ou alterar um comportamento especifico (Mantovani, 2007).

Estes estágios e suas características gerais são:

- Pré-contemplação - quando não se tem a intenção de modificar o comportamento em um futuro próximo.

- Contemplação - começa a gerar uma intenção de modificar o comportamento, mas ainda não se compromete com a tomada de ação efetiva.

- Preparação - demonstra-se prontidão para iniciar a prática de atividade física em um futuro próximo ou realizar uma prática sem regularidade e pequenas mudanças de comportamento começam a acontecer.

- Ação - é o momento em que a pessoa está empenhada em mudar e adquirir um estilo de vida regularmente ativo em que nítidas mudanças são observadas.

- Manutenção - permanência na prática de atividade física regular por mais de seis meses tornandose um hábito. 
Considerando a aplicabilidade do MTT como estratégia de modificação de comportamento, este estudo se propôs a relatar a experiência resultante da proposta de trabalho do projeto Escola do Esporte desenvolvidas há quatro anos no Brasil e observar os efeitos da adesão às atividades físicas oferecidas na formação humana desde o ponto de vista filosófico e dos princípios que embasam tal projeto.

Para melhor compreensão de cada estágio, foi realizado o estudo através de uma pesquisa de campo, descritiva, com abordagem qualitativa e quantitativa de corte transversal. A parte quantitativa utilizou a amostra do tipo conveniência. Considerou-se como população todos os atletas que participam ou participaram da Escola do Esporte e, como amostra de conveniência, todos os atletas que participaram das Olimpíadas. A amostra foi constituída por 180 atletas dos sexos feminino e masculino participantes de Jogos Olímpicos amadores para o ano de 2015, 161 para o ano de 2017 e 282 atletas para o ano de 2019, existindo participantes de nove Estados brasileiros já mencionados, distribuídos em 27 filiais ou sub-escolas.

A percepção dos estágios de comportamento foi acompanhada por meio de relatórios e reuniões mensais com os instrutores responsáveis por cada Estado. Os resultados alcançados pelo projeto em questão serão apresentados na sequência pelo relato da experiência pedagógica desenvolvida pela Escola do Esporte, centrada na filosofia do Olimpismo, bem como alguns gráficos ilustrando a participação dos atletas ao longo dos anos.

Na parte de exploração dos dados o software usado para esse trabalho foi o $R$ versão do $R 3.2 .4$, sendo escolhido por ser um software de boa qualidade e de acesso gratuito. Utilizou-se também como ferramenta de gráficos o programa Qlik Sense Desktop June 2019, na versão 13.32.2.

\section{DISCUSSÃO}

\section{Relato da Experiência: apresentação da metodologia de ensino}

A Escola do Esporte é oferecida como atividade complementar aos alunos do curso de filosofia da Nova Acrópole por meio de diversos ateliês ${ }^{3}$, destinados a pessoas que queiram praticar atividade física esportiva para aplicação na vida diária - independente de idade, gênero ou qualquer outra característica física - e experienciar o desenvolver-se como atleta ${ }^{4}$ em seu sentido clássico, ou seja, conforme a conceituação apresentada na filosofia. Para tanto, busca-se lograr em alguma medida uma formação integral de ser humano, tal qual propunha Platão - com suas ideias de música e ginástica, especialmente apresentadas na obra A República - e Coubertin - com a proposta de pedagogia esportiva, centrada no desenvolvimento harmônico do indivíduo - (Müller \& Todt, 2015).

A oferta dos ateliês varia conforme a estrutura de cada filial e a disponibilidade de instrutores para conduzir as práticas com frequência regular e a formação adequada; os instrutores devem ser também instrutores de filosofia. As atividades são desenvolvidas a partir de um planejamento anual, levando em conta as individualidades e objetivos iniciais de cada integrante, bem como as atividades de "apresentação" do trabalho desenvolvido, como as Olimpíadas Nacionais, que desde 2015 acontecem com frequência bianual,

\footnotetext{
${ }^{3}$ Variam conforme cada filial, norteado pelas modalidades olímpicas deste contexto - atletismo, voleibol, natação, tênis de mesa e xadrez.

"A palavra 'atleta' deriva do grego athlon, e traz o significado de "o que compete por um prêmio". Outro significado para a tradução de athlon a define como "aquele que luta", estando mais alinhada com a concepção na qual a Escola do Esporte se ancora, posto que, hoje, o tema das competições parece estar mal compreendido. Na origem latina do termo, "competire" significa na realidade ir junto até algum lugar. Em resumo, a partir da visão filosófica clássica, ser um atleta implica estar disposto a lutar para desenvolver o que tem de melhor, de educar sua vontade para conquistar o máximo do seu potencial humano.
} 
intercalando com as Olimpíadas Internacionais a cada quatro anos (primeira edição realizada em 2018, na Espanha).

A frequência de encontros para se constituir um ateliê é dada por, no mínimo, atividades mensais, sendo a frequência semanal o ritmo ideal. Os encontros precisam atender minimamente aos critérios platônicos práticas corporais (ginástica) e formação filosófica (música). Além da experiência prática dos treinos, 0 enfoque filosófico dado para cada atividade ocorre por meio do programa de formação composto por aulas mensais com temas de fundamentação investigativa-filosófica, onde a filosofia olímpica ganha fundamental importância.

Os conteúdos transmitidos perpassam desde a compreensão histórica do Ideal Olímpico até a sua vivência nos dias atuais, bem como reflexões sobre o sentido das práticas esportivas, dos símbolos e cerimônias que as compõem, virtudes e valores a serem desenvolvidos. Por meio do diálogo habitual se compartilha como cada um está lidando com a aplicabilidade do treinamento na própria vida, além da apresentação voluntária de reflexões sobre o conhecimento teórico e sua relação com a prática cotidiana. Desta forma, busca-se construir o pilar "música e ginástica" como eixo da educação desse ser humano integral almejado pelo ideal grego e também vislumbrado por Coubertin.

No que se refere às sessões de treinamento, iniciam com um momento de reflexão sobre um aspecto a ser trabalhado - que pode variar conforme a percepção do treinador em relação às necessidades do grupo - ou tema prévio de estudo visto nas aulas teóricas. Na sequência, parte-se para a execução física - aquecimento e parte principal - e, a última meia hora, é dedicada a realizar uma prática de respiração e relaxamento, seguido de uma de roda de reflexões sobre o que foi vivenciado na sessão e, principalmente, o que é possível extrair de aprendizados práticos. Tal condução é intermediada pelo instrutor que instiga a fala do grupo, funcionando como o momento de "avaliação" da atividade e de acompanhamento dos integrantes.

Em termos de avaliação do acompanhamento do trabalho em âmbito nacional, mensalmente é realizado um relatório de acompanhamento das atividades feito pelo instrutor responsável por cada Estado e, principalmente, do desenvolvimento de cada integrante de maneira integral. Observa-se não apenas a participação nos ateliês e vivências dos valores olímpicos durante as práticas em si, mas sobretudo nas demais atividades e aspectos da vida cotidiana, a partir de uma perspectiva concreta de se está havendo transformação na maneira de viver no dia a dia, com o intuito de realizar um acompanhamento integral do desenvolvimento filosófico.

Quanto aos desafios encontrados e suas relações com os estágios de mudança comportamental, percebese que 0 aspecto motivacional é sem dúvida um dos maiores desafios enfrentados na condução das atividades da Escola do Esporte. Além disso, considerando que se busca algo como um caminho de desenvolvimento pessoal, isso tem implicações, indubitavelmente, em mudanças de conduta. De acordo a Prochaska et al. (1992), as mudanças de conduta podem ocorrer quando há um processo de ampliação de consciência. Segundo os autores, o início de qualquer mudança comportamental está relacionado ao conhecimento que as pessoas têm em relação aos malefícios das suas ações - nesse caso, em relação a saúde -, bem como quais serão os benefícios (ou recompensas) para justificar o esforço da mudança.

Assim, um dos obstáculos iniciais enfrentados para decidir-se por participar das atividades da Escola do Esporte está em realizar esse movimento de ampliação da consciência. Para os instrutores significa evidenciar motivos capazes de impulsionar os alunos a experimentarem as práticas e assim aumentar a sua 
intenção para adoção das mesmas (Prochaska et al., 1992). Isto é, mover-se do estágio da précontemplação para a etapa da contemplação.

Os autores apontam que há dois elementos centrais para ajudar na transição desse primeiro estágio, que são a autoeficácia, que diz respeito às habilidades físicas e psicológicas do sujeito e a intenção, que se refere à inclinação para realizar algo, atrelada à obtenção de um prêmio. A pesquisa apontou que para os alunos nesse estágio, grande parte dos mesmos demonstrava interesse em iniciar as práticas ou bem pela conquista de um corpo mais saudável e/ou bonito, ou bem para experimentar um senso de pertencimento ao integrar uma equipe/time no âmbito das relações pessoais/sociais.

Nesse sentido, algumas das ações efetuadas para trabalhar o elemento da intenção foi realizar exposições verbais para promover as finalidades da Escola do Esporte a partir de imagens e vídeos, além do depoimento dos monitores e de praticantes, enfatizando, sobretudo, a visão filosófica em relação à prática esportiva. Procurou-se para tanto ampliar a compreensão de que os objetivos almejados vão além da obtenção da saúde biológica, uma vez que a proposta do método visa utilizar-se das práticas esportivas como ferramentas de fortalecimento em todas as dimensões - física, psicológica e mental ou, como diriam os gregos, corpo, mente e alma.

Dessa forma, buscou-se demonstrar que por meio da Escola do Esporte se promove o desenvolvimento integral do ser humano, inspirado no ideal grego, de trabalho sobre a mente (desenvolvimento intelectual), tal qual sobre o físico, cultivando o ideal de beleza, saúde e virtude, nessa concepção mais ampla.

Nessa etapa, verificou-se que um dos fatores limitadores para o início da prática estava no fato de que muitas pessoas sentiam vergonha, seja do seu corpo ou como algum medo de não ser aceita pelo grupo, devido a um pré-julgamento pessoal de não possessão de habilidades físicas adequadas. A fim de contornar essa resistência, enfatizou-se outro elemento central da proposta do trabalho, que são os valores humanos que norteiam todas as ações. Dentre eles, destaca-se o valor da convivência - elemento essencial para nos aproximarmos da conquista da $\mathrm{Paz}^{5}$ entre os povos como idealizou Coubertin ao promover os Jogos Olímpicos em esfera global.

A partir do momento em que os alunos percebiam que os atletas da Escola do Esporte estavam imbuídos por esse espírito de fraternidade, regidos por outra lógica de competição e sobre o que representa a verdadeira vitória, observou-se uma maior inclinação para começar a participar de algum ateliê.

Outra resistência constatada no estágio da pré-contemplação foi em relação a autoeficácia - percepção de si mesmo -, que fazia com que os alunos não se sentissem capazes de iniciar. Era comum ouvir a seguinte resposta diante do convite para participar das atividades:" mas eu não jogo bem vôlei" (ou qualquer outra modalidade). Além de procurar contornar tal justificativa indicando que a pergunta não se trata de saber jogar bem ou não, mas simplesmente se havia o interesse em participar, outro aspecto trabalhado sobre esse padrão de comportamento foi mostrar que qualquer pessoa tem condição de ser um atleta e se desenvolver através do esporte sob essa perspectiva filosófica. Com base na indicação de Coubertin (Muller \& Todt, 2015, p. 755) de que o esporte é para todas as pessoas, "patrimônio de todas as raças (...) e sua ausência não pode ser substituída por nada", enfatizou-se que o único requisito para começar era ter interesse em experimentar e participar de um treino.

\footnotetext{
${ }^{5} \mathrm{Na}$ atualização da filosofia do Olimpismo, redigida através da Carta Olímpica atual, essa ideia pode ser entendida como o valor
} da Amizade, um dos três pilares que atualmente compõe o lema olímpico, juntamente com as ideias do Respeito e da Excelência. 
Percebeu-se que com essas iniciativas se conseguia ajudar a fortalecer intenções e autoeficácia, e de fato mobilizar um percentual de alunos a mudar para o estágio seguinte, o da preparação. A literatura apresenta que se pode permanecer no estágio da contemplação por longos períodos de tempo, tendo consciência da importância de se praticar atividade física, mas sem aderir a ela (Mantovani, 2007).

Adentrando no estágio da preparação, as pessoas passam a demonstrar sérias intenções de modificar seu comportamento e colocam-se prontos para iniciar em um futuro próximo, ou mesmo começar sem regularidade. Nesse momento, entende-se ser essencial a existência de várias oportunidades de engajar a participação; por esse motivo, se promove a abertura de diversos ateliês, com modalidades distintas, em horários e locais diferentes para viabilizar o envolvimento.

Através da metodologia aplicada pela Escola do Esporte, favorecemos a transição para essa etapa, uma vez que por meio dessa experimentação de diferentes práticas sob esse viés formativo, permite-se que as pessoas explorem novas possibilidades e possam descobrir a si mesmas em diferentes e, por vezes, novos aspectos, percebendo na prática todos os benefícios do esporte sob a luz da filosofia do Olimpismo.

Nessa direção, uma iniciativa válida que observamos em relação ao comportamento dos alunos dentro dessa etapa, ocorrida no estado do Rio de Janeiro, foi a promoção do evento que inicialmente se chamou de Seletiva Olímpica. Como o nome sugere, se tratava de uma competição para definir quais atletas seriam selecionados como representantes de suas equipes nas Olimpíadas nacionais. Foi surpreendente que houve um número de inscritos abaixo do esperado. Isso foi o impulso a mudar a nomenclatura do evento e promovê-lo como "apresentação das modalidades olímpicas" e o resultado novamente surpreendeu: houve um aumento considerável do número de participantes e avaliação geral do evento foi muito positiva a partir da finalidade de promover a experimentação de novos integrantes.

O aprendizado dessa experiência foi replicado para os demais Estados e o mesmo efeito foi constatado; menor resistência à participação diante desse ajuste de linguagem, viabilizando a integração de um maior número de participantes. Foi possível perceber que tal experimentação permitiu às pessoas constatarem que eram mais capazes do que inicialmente imaginavam, aumentando a confiança em si mesmas, passando a consolidar suas motivações e forças para seguir à etapa da ação propriamente, e se engajar a um ateliê com frequência regular, adquirindo um novo hábito consolidado.

A estruturação das atividades através dos ateliês, como detalhado acima, está centrada no pilar de educação platônica de música e ginástica. Pode-se dizer que, de maneira geral, todo o treinamento está direcionado para a participação nas Olimpíadas Nacionais, pois se entende (por meio dos relatos, observações e também por experiência prática dos autores) que a vivência dessa "Festa do Esporte", nos moldes das cerimônias clássicas, permitem um maior entendimento do sentido da prática esportiva, capaz de gerar um novo impulso de motivação que leve o praticante a sustentar o seu comportamento, conquistando o patamar da manutenção.

Quando se menciona a participação nas Olimpíadas, vale ressaltar que não se trata de participar apenas na condição de atleta que irá atuar em alguma modalidade propriamente, mas, sendo coerente com 0 entendimento do sentido clássico dos termos que se propõe o resgate, consideram-se atletas todos aqueles que estão dispostos a competir para triunfar sobre seus próprios temperamentos. Ademais, sendo o esporte para todos, não participam das Olimpíadas apenas aqueles que representam suas equipes nas quadras, pistas, piscinas ou tabuleiros, mas todos aqueles que fazem parte dessa busca comum para se chegar juntos ao melhor de si mesmos, em uma competição pela expressão do autêntico espírito humanista, seja 
como torcedor, colega de treino, voluntário de apoio no evento e entre outros. Assim, todos que compartilham desse mesmo Ideal são considerados partícipes dessa "família olímpica", como diria Coubertin, onde todos são chamados e igualmente estimados a desfrutar dessa vitória coletiva.

Inclusive, à medida que as marcas obtidas nas modalidades foram melhorando, os índices mínimos balizadores da participação nos Jogos foi se elevando na mesma proporção, não com um caráter de exclusão, mas sim sob um viés pedagógico, no sentido de se obter superações internas. Outras medidas foram tomadas para viabilizar maior participação - como criação de novas modalidades e número irrestrito de atletas nas modalidades de vôlei (bem como quantidade de substituições) e da corrida dos $5 \mathrm{~km}$. Assim, pode-se notar um crescimento na intenção de participar das Olimpíadas conforme se constatava que aumentava a motivação dos alunos em experimentar a vivência em equipe, fazer novas amizades, jogar, torcer ou ajudar na realização dos Jogos como voluntário.

Segundo a literatura, o estágio da manutenção é quando a pessoa permanece na prática de atividade física regular por mais de seis meses, incorporando-a como um hábito. Nesse sentido, percebe-se a participação nas Olimpíadas como um elemento chave para fortalecer a disposição em evitar recaídas, mesmo quando a pessoa já se encontra na etapa da manutenção, robustecendo suas convicções e confiança em si mesma.

Como uma forma de ajudar cultivar a motivação vivida na experiência Olímpica na continuidade do treinamento, vídeos e revistas com o depoimento dos atletas são confeccionados para favorecer a lembrança da experiência. Contudo, mesmo com todos os esforços, existe a possibilidade de recaída. Assim, esse é um ponto de atenção e de empenho por parte dos coordenadores ao longo das diferentes etapas, acompanhamento esse que exige além de muita atenção, disponibilidade de tempo. Como o trabalho é voluntário, muitas vezes não se encontra disponibilidade para dar atenção ao atleta no momento da recaída, sendo esse um dos aspectos a seguir aperfeiçoando no trabalho.

A partir da experiência de condução das atividades ao longo dos quatro anos, constata-se a importância do instrutor para impulsionar e acompanhar a transição de cada etapa, sobretudo para ajudar os praticantes a se manterem no estágio da ação, sendo capazes de sustentar o comportamento adquirido ao longo do tempo. Uma vez que a maior finalidade almejada por meio das práticas esportivas é o desenvolvimento harmonioso do indivíduo em todas suas dimensões, essa certamente se trata de uma conquista a ser buscada por toda a vida. Desse modo, entende-se o esporte como de fato para todos e por todo o tempo possível, ao longo da vida.

\section{RESULTADOS}

O gráfico de mapa (Figura 1) mostra a participação de atletas nas Olimpíadas do voluntariado, promovida pela Escola do Esporte em parceria com Nova Acrópole e sua evolução ao longo dos anos de 2015, 2017 e 2019. Em 2015, 180 atletas de inscreveram, em 2017 nota-se uma pequena queda no número de participantes, 161 atletas. Neste evento, a Escola do Esporte implanta um modelo mais estruturado, baseado nos princípios de Pierre de Coubertin e da Grécia Antiga, com protocolo bem definido para os Jogos e para a cerimônia de abertura e fechamento. Antes de 2017, as competições aconteciam simultaneamente, a partir desse ano, passou-se a realizar a competição de uma modalidade por vez, o que permitiu uma maior participação do público.

A abertura da cerimônia olímpica se tornou mais extensa, com entrada das delegações, bandeiras, juramento dos atletas na promoção da união e do respeito por regras e pelo espírito olímpico, assim como 
dos juízes em relação à busca do justo e verdadeiro. A implantação dessa metodologia gerou grande satisfação e uma propaganda imediata entre os demais atletas que não puderam participar do evento. Isso levou a inscrição de 282 atletas em 2019, um aumento de cerca de 75\% das inscrições. 0 mesmo crescimento aconteceu para o público. $O$ evento também foi registrado e postado no youtube, o que pode ter contribuído com o crescimento.

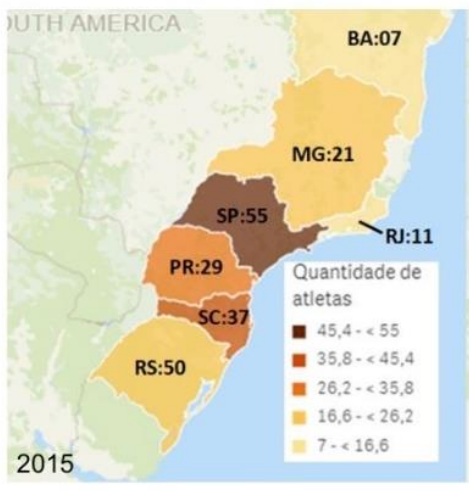

2017

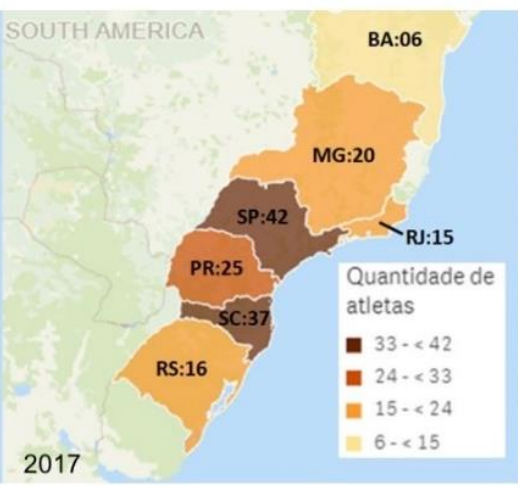

Fonte: Coleta de dados, 2019.

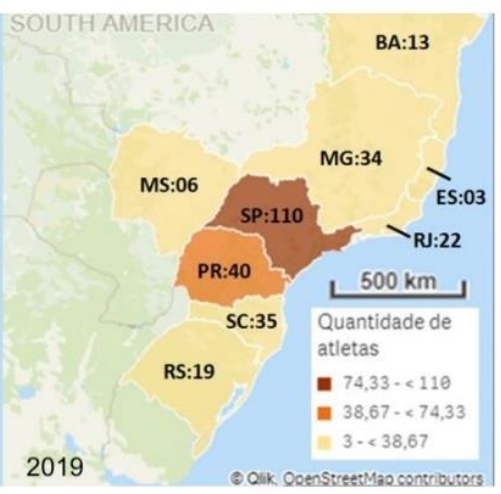

2019

Figura 1. Participação anual de atletas distribuída por estado.

A maioria dos Estados tem mostrado uma evolução numérica em relação à participação dos atletas, com exceção de Paraná e Santa Catarina que mantém o mesmo número de atletas participantes no projeto. 0 destaque de maior crescimento se dá no estado de São Paulo, com um crescimento de $162 \%$ no ano de 2019 em relação a 2017. Este crescimento percentual se dá devido à maior facilidade de acesso a espaços para atividade física e devido ao preparo das pessoas que coordenam o projeto. A falta de local para 0 desenvolvimento dos ateliês é um fator de grande dificuldade em muitos Estados do Brasil.

A participação das mulheres aumentou também de 2017 em diante, como pode ser constatado no gráfico da Figura 2. Em 2015, 68\% dos atletas eram homens e 32\% mulheres. Depois do novo protocolo, 0 percentual de participação das mulheres subiu para 40\%, mantendo esse percentual nos dois últimos eventos. É natural imaginar que essa maior participação dos homens ocorreria, já que estudos mostram que a prática esportiva na sociedade é mais comum para o sexo masculino (Ferez et al, 2018).

A inserção das mulheres nas Olimpíadas se deve em grande parte ao esforço de Alice Milliat ${ }^{6}$, que deu continuidade a muitos projetos de Coubertin. A Escola do Esporte se alinha a essa meta e espera aumentar ainda mais o percentual de participação das mulheres buscando um equilíbrio em comparação à participação dos atletas de sexo masculino.

A Tabela 1 mostra a evolução da participação dos atletas nas diferentes modalidades. 0 ano de 2019 superou todas as marcas de participação com exceção do salto em altura, que manteve o mesmo número de participantes nos três anos. Segundo os relatos dos voluntários, isso ocorreu diante da dificuldade de encontrar um espaço e implementos para o treinamento. Novas modalidades são apresentadas e alguns atletas começam a se identificar com esses eventos que não são tradicionalmente praticados, como 0 arremesso de peso e o salto em distância.

6 Alice Miliat (1884-1957): francesa pioneira na inclusão do esporte feminino no mundo. Fonte: https://fondationalicemilliat.com/en/alice-milliat-2/. Acesso em 13 de nov. 2019. 


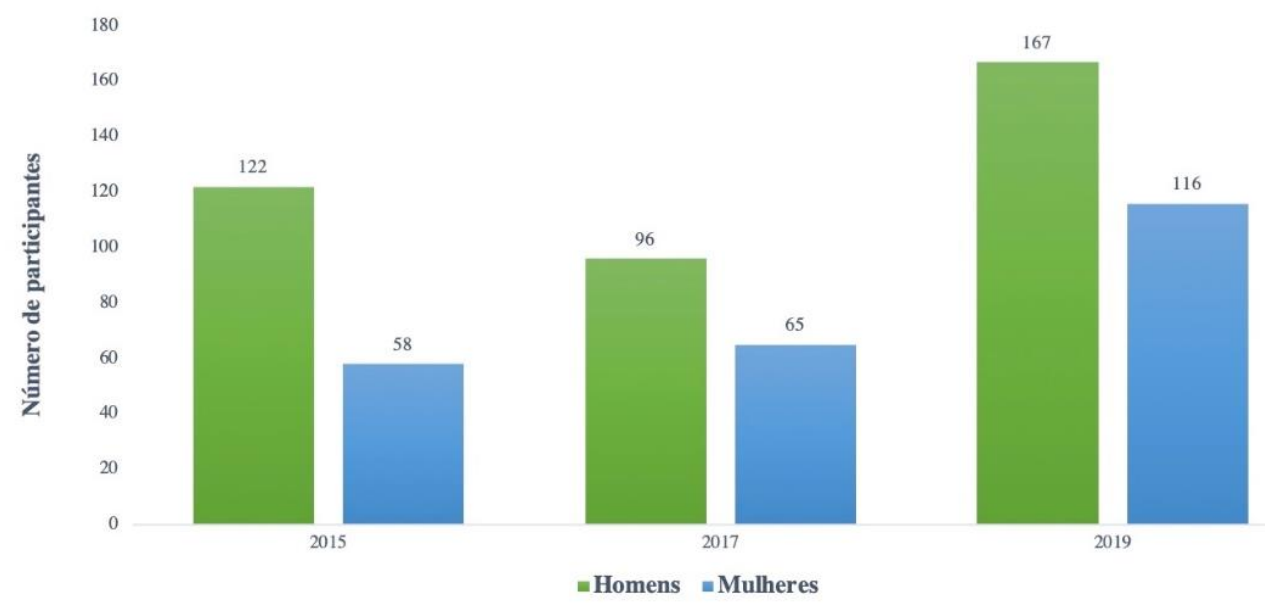

Fonte: Coleta de dados, 2019.

Figura 2. Distribuição anual de participantes por gênero.

Os esportes coletivos têm maior adesão dos atletas, porém como os Jogos acontecem em finais de semana e os esportes como vôlei, basquete e futebol exigem mais tempo para serem realizados, não se dispõe de tempo suficiente durante o final de semana para implementar todas essas atividades. Além disso, modalidades que utilizam maior contato corporal aumentam os riscos de ocorrer lesões e uma equipe médica seria imprescindível para a segurança do evento.

Tabela 1. Distribuição de participantes por ano, gênero e modalidade.

\begin{tabular}{|c|c|c|c|c|}
\hline Participantes & Modalidade & 2015 & 2017 & 2019 \\
\hline \multirow{11}{*}{ Mulheres } & $4 \times 100 \mathrm{~m}$ & 11 & 12 & 23 \\
\hline & $100 \mathrm{~m}$ & 9 & 10 & 22 \\
\hline & $800 \mathrm{~m}$ & 10 & 9 & 17 \\
\hline & $5 \mathrm{~km}$ & - & 13 & 49 \\
\hline & Arremesso de peso & - & 7 & 11 \\
\hline & Natação & 5 & 5 & 15 \\
\hline & Salto em altura & 2 & 2 & 2 \\
\hline & Salto em distância & 2 & 2 & 4 \\
\hline & Tênis de Mesa & 5 & 4 & 7 \\
\hline & Vôlei Misto & 33 & 39 & 41 \\
\hline & Xadrez & 5 & - & 7 \\
\hline \multirow{12}{*}{ Homens } & $4 \times 100 \mathrm{~m}$ & 17 & 24 & 49 \\
\hline & $5 \mathrm{~km}$ & - & 23 & 58 \\
\hline & $100 \mathrm{~m}$ & 33 & 20 & 40 \\
\hline & $800 \mathrm{~m}$ & 15 & 15 & 27 \\
\hline & Arremesso de peso & - & 10 & 16 \\
\hline & Natação & 12 & 4 & 20 \\
\hline & Salto em altura & 3 & 1 & 7 \\
\hline & Salto em distância & 7 & 7 & 13 \\
\hline & Tênis de Mesa & 14 & 18 & 33 \\
\hline & Vôlei Misto & 37 & 40 & 65 \\
\hline & Xadrez & 17 & - & 40 \\
\hline & Futebol & 64 & - & - \\
\hline
\end{tabular}

Fonte: coleta de dados, 2019. 


\section{CONCLUSÃO}

O esporte não é só exercício para estar atlético, senão que pode ser também uma via de crescimento e superação de todos. Um programa bem estruturado em cima dos valores olímpicos pode construir um ser humano mais realizado, feliz consigo mesmo e capaz de conviver melhor com os demais. Os relatos dos atletas demonstram um maior domínio das emoções após o treinamento desportivo-filosófico, pontuando uma melhor capacidade de lidar com as frustações da vida. Como diz Coubertin, o Olimpismo é um estado de ânimo, que pode ser construído através do esporte e permite a todos desfrutas da vitória de sentir a alegria do esforço.

Verificou-se que $33 \%$ dos atletas de uma Olimpíada estavam presentes na edição seguinte. Isso não significa distanciamento do programa, pois uma boa parte não pode participar dos Jogos por motivo de trabalho, por motivo financeiro ou por não ter atingido as marcas mínimas. Muitos participaram como público e voluntários, porém estes casos não foram computados no estudo. No entanto, uma limitação constada na realização do presente estudo foi a impossibilidade de estudar todos os participantes da Escola do Esporte no Brasil, restringindo aos que participaram das Olimpíadas.

A metodologia aplicada pela Escola do Esporte demonstra favorecer o processo de ampliação de consciência, permitindo a transição entre os estágios de mudança comportamental, sendo efetiva em promover motivação para consolidação do hábito de praticar atividade física regularmente. Dentre os diferenciais oferecidos como impulso para a mudança, o benefício de promover um fortalecimento harmonioso do indivíduo em todas as dimensões, associado o sentido filosófico às práticas, parece ter sido o principal motor.

Como conclusão principal, a pesquisa apontou consistentes vestígios de que a formação baseada na filosofia do Olimpismo contribui para o fortalecimento psicológico dos atletas e a conquista de uma motivação mais duradoura e consciente.

\section{REFERÊNCIAS}

Amat, M. \& Batalla, A. (2000). Deporte y Educacion em Valores. Revista Candidus, Año 1, no 12, Nov/dez.

Bento, J.O. (2007). Do Desporto como um Projeto Ético. Para uma mudança nas mentalidades e atitudes. In: Rubio, K; et. al. Ética e Compromisso Social nos Estudos Olímpicos. Porto Alegre: EDIPUCRS.

Carta Olímpica (2015). Comité Internacional Olímpico. Laussanne, Switzerland.

Carvalhedo, A. \& Da Costa, L. (2000). Educação Olímpica: Pesquisa de campo para validação de um modelo adaptado à realidade brasileira. Fórum Olímpico 2000: O Movimento Olímpico em Face do Novo Milênio, Porto Alegre, p. 2-7. Disponível em: http://www.cenesp.uel.br/livros/forum?texto.pdf

Ferez, S. et al. (2018). Sports and 'Minorities': Negotiating the Olympic Model. Sport, Ethics and Philosophy, v. 12, no 2, pp. 177-193. https://doi.org/10.1080/17511321.2017.1341948

Gomes, M. C. (1999). Solidariedade e Honestidade: os fundamentos do fair-play entre adolescentes escolares. In Tavares, O. \& Da Costa, L. (Eds.) Estudos Olímpicos. Rio de Janeiro: Editora Gama Filho.

Gomes, M. C. \& Turini, M. (2004). Esporte, Ética e Intervenção no Campo da Educação Física (2004). In Tojal J.; Da Costa, L. \& Beresford, H. (Orgs.). Ética Profissional na Educação Física. Rio de Janeiro: Shape. https://doi.org/10.17648/galoa-cbee-6-28715 
Meurer, S. T. (2008). Motivos para a prática de atividades físicas de idosos: uma revisão sistemática dos instrumentos utilizados para mensurar a motivação. Estudos Interdisciplinares sobre 0 Envelhecimento, v. 13, n. 2, pp. 191-203. https://doi.org/10.5216/rpp.v13i3.10946

Mantovani, E. P. (2007). Atividade Física, Saúde e Envelhecimento. In: Vilarta, R. \& Sonati, J. G. (Org.) Diagnóstico da Alimentação Saudável e Atividade Física na Fundação de Desenvolvimento da Unicamp. Campinas: Ipes. Cap. 9. p. 65-72. Disponível em: < https://www.fef.unicamp.br/fef/sites/uploads/deafa/qvaf/funcamp_completo.pdf>. Acesso em: 13 nov. 2019.

Molina Neto, V., \& Bossle, F. (2010). O ofício de ensinar e pesquisar na Educação Física escolar. Porto Alegre: Sulina.

Müller, N. \& Todt, N. (2015). Pierre de Coubertin: seleção de textos. Porto Alegre: EDIPUCRS.

Parry, J. (1998a). Physical education as olympic education. European Physical Education Review, v. 4, $n^{0} .2$, pp. 153-167. https://doi.org/10.1177/1356336x9800400206

Parry, J. (1998b). The justification of physical education. In: Green, K. \& Hardman, K. (eds), Physical education -a reader. Aachen: Meyer and Meyer, pp. 36-68.

Parry, J. (2006) Sport and olympism: universals and multiculturalism. Journal of the Philosophy of Sport, v. 33, nº. 2, pp. 188-204. https://doi.org/10.1080/00948705.2006.9714701

Prochaska, J. O.; DiClemente, C. C. \& Norcross, J. C. (1992). In search of how people change: applications to addictive behaviors. American Psychologist, v. 47, $n^{0}$. 9, pp. 1102-1114. https://doi.org/10.1037/0003-066x.47.9.1102

Toral, N., \& Slater, B. (2007). Abordagem do modelo transteórico no comportamento alimentar. Ciência \& Saúde Coletiva, v.12, n. 6, pp. 1641-1650. https://doi.org/10.1590/s1413-81232007000600025

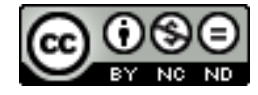

This work is licensed under a Attribution-NonCommercial-NoDerivatives 4.0 International (CC BY-NC-ND 4.0). 